\title{
Urban Development and Water Management in the Yangtze River Delta
}

\author{
Yan Wang ${ }^{1,2 *}$, Wei $\mathrm{Wu}^{3}$ \\ ${ }^{1}$ School of Architecture, Southeast University, Nanjing, China \\ ${ }^{2}$ Center for Mobility and Spatial Planning, Ghent University, Ghent, Belgium \\ ${ }^{3}$ Jiangsu Institute of Urban Planning and Design, Nanjing, China \\ Email: yan.linda.wang@hotmail.com
}

How to cite this paper: Wang, $\mathrm{Y}$. and $\mathrm{Wu}$, W. (2018) Urban Development and Water Management in the Yangtze River Delta. World Journal of Engineering and Technology, 6, 13-23.

https://doi.org/10.4236/wjet.2018.62B002

Received: February 10, 2018

Accepted: May 19, 2018

Published: May 22, 2018

\begin{abstract}
Throughout the history of the world, the development of the cities are related to the large water systems and the ocean. Where the river is abundant, the trade and regional centres could be formed. However, along with the prosperity of the water-cities, massive urban construction and environmental issues are enormous challenges in human process. A "scientific" urban planning, "Sponge City", "Resilient City", regional and urban culture and characteristics get more and more attention. The theme of "water and city" is clearly of great historical value and practical significance for the new resilient urban and water management strategies. The paper will summarize characteristics of geographical, historical, socio-cultural and political realms in metropolitan deltas and the historical governance as well as the recent developments in the Yangtze River Delta. It will introduce urban development and water management in four water cities: the canal and the city-Yangzhou, the river and the city-Nanjing, the lake and the city-Suzhou and the sea and the city-Shanghai. And then it will analyze the inner motivation of the interaction between water and cities in Yangtze River Delta. Furthermore, learning from successful historical experiences, the paper will provide suggestions for future sustainable urban development.
\end{abstract}

\section{Keywords}

Yangtze River Delta, Water Cities, Urban Development, Delta Governance, Resilience

\section{Introduction}

The Chinese government has issued a series of documents to manage and guide the urban planning. In March 2014, they promulgated "The state's new urbani- 
zation development plan (2014-2020)", pointing out that some historical cities in China do not pay attention to the excavation and inheritance of history and culture, the "constructive" destructions are spreading, the natural and cultural personalities are destroyed. In view of these problems, the "planning" suggest the urban construction should adhere to the "cultural heritage, highlight the characteristics of different regions according to the natural history and cultural endowment, reflecting the regional differences, to promote the diversity of species, and develop with historical memory, cultural context, geographical features, and ethnic characteristics of the beautiful towns, forming realistic, distinctive urbanization development model".

For thousands of years, most people chose to live nearby water. The historical and cultural heritages of many cities are also closely related to the coastal shoreline, from China's Jiangnan water countries to the seaside ports in Europe, and to the current global urban waterfront space transformation and regeneration, always the same. In many cases, the waterfront is often located in the heart of the city and has a rich industrial heritage and a unique waterfront landscape. The metropolitan waterfront began to undergo a process of transformation and regeneration that from the former industrialized river sides, began to be transformed into a post-industrialized place of residence-work-leisure and were again favored by residents, investors and tourists [1].

The theme of "water and city" is clearly of great historical value and practical significance. How could we protect the pattern of traditional water towns in today's conditions, integrate the historical landscape of the water and realize the sustainable planning of the ecological environment? And whether we could re-examine the relation of "water and city" from the historical development process, and draw the historical experience to provide a reference for the further sustainable progress. Thus, city research should be based on the history and look to the future.

Through the ancient city maps illustration, literature reading, information collection and other means, the paper will take Yangtze River Delta as an example, take Yangzhou, Nanjing, Suzhou and Shanghai as the case cities, introducing the influence of water system (natural and artificial) on urban development. And then it will analyze the delta governance of Yangtze River Delta in different periods. Moreover, learning from successful historical experiences, the paper tries to provide suggestions for future sustainable development.

\section{Water Cities in the Yangtze River Delta}

The Yangtze River Delta is presented in seven spatio-cultural stage characteristics in regard to water-city interaction: Early Physical Geography and Settlement Development $(<4000 \mathrm{BC})$, The formation of the city $(<-200 \mathrm{BC})$, The first canal-urban system (250BC-600AD), Grand Canal urban system (550AD-950AD), Water-cities (900AD-1400AD), Diversification of urban development (1350AD-1850AD), The rise of railways and the urban national industry 
(1800AD-1950AD) [2]. Water cities of Yangzhou, Nanjing, Suzhou and Shanghai witnessed the historical development of the Yangtze River Delta. The water environment promoted and affected these cities' development at different times.

\subsection{Yangzhou: From a Small Canal City to the Southeast Metropolis}

\subsubsection{Han Canal Constructed the City}

In $486 \mathrm{BC}$, the king of Wu built up a "Han city" in the northwest of present-day Yangzhou, for garrison and storing the food. As such Han City (Yangzhou) was formerly a military frontier fortress in order to contend for hegemony of "Wu". The city of Yangzhou at first a formal, military constructed city, gradually became a central town in eastern China.

In Han Dynasty (202BC-220AD), Guangling (Yangzhou) was the fiefs for a long time. The vassal-states of Jing, $\mathrm{Wu}$, Jiangdu, and Guangdu set the first state and capital here. The kings of Wu proposed the policy "boiling sea water for salt production", promoting the economic development in first time of Yangzhou's history. In Three Kingdoms period (220-280AD), Guangling (Yangzhou) became the military stronghold in the area between Huai River and Yangtze River.

\subsubsection{Canals Thrived the City}

Being a military stronghold originally, due to the digging of canals, Yangzhou became a main hub of China's north-south traffic. It became not only a trading centre for food, salt, money, and iron, but also a window for international exchange. Merchants and emissaries gathered at Yangzhou from all over the world. The abundant resources and prosperity of the city triggered the establishment of factories and handicraft workshops, the commerce of Yangzhou presented an unprecedented prosperity. In the south of the location of Han city, along the canal, it formed businessmen communities, called "Luo city". Including the former area of the city, twofold city pattern came into being Yangzhou of Tang Dynasty.

However its military function also remained strongly. For the sufficient defence, the city of Yangzhou formed a special pattern consisting of "Zhou City", "Bao City" and "Jia City" in Song Dynasty. Yangzhou shifted from a commercial city and the economic centre into the forefront strategic important place, marking Yangzhou's prominent military status.

In Ming and Qing Dynasties, however the convenient grain-transport by water and the brisk salt-trade had brought once again the dazzling prosperity in Yangzhou. A "New city" was constructed based on the southwest areas of Yangzhou's location of Song Dynasty. A new business centre of docks, warehouses, hotels, restaurants and private homes of many rich merchants were concentrated in this region.

The canals had a significant influence on urbanization of Yangzhou, not only the changes of the city's location, but also on the urban development and city life. Due to the transporting, a lot of new type functional architectures were built 
along the canals, as like warehouses, shaoguan, piers and so forth. Shaoguan, was one part of the canal revenue system, charging the taxes from the boats that passed through. Many professional streets in the "New city" were spontaneous formed because of the canals, which became the communities of some industry, that could be seen from the street's names, such as color clothing street, sesame lane and so on. The canals also brought Yangzhou's salt industry and business prosperity. The salt merchants lived along the canal, and contructed a large number of guilds and markets (Figure 1).

\subsection{Nanjing: From the Ancient Capital of the Six Dynasties to the Capital of Jiangsu Province}

From 211 AD, Nanjing was set as the capital of Sunwu Period, called Jianye at that time. Qinhuai River located in the south, between the Qinhuai River and the Yangtze River, Hou Lake, Chao Canal, Jinchuan River, Qing River and Yundu Canal, such waterways composed Nanjing's water network, contributing to the city's water supply and transport. And then Nanjing was set as the capital of successive dynasties: Eastern Jin, Song, Qi, Liang, and Chen, called Jiankang. Due to the large waves of the Yangtze River, Pogang Canal and Shangrong Canal were erected respectively in Dongwu (222-280AD) and Liang Period (502-557AD) for transporting, linking Qinghuai River and Taihu Lake. In the Six Dynasties, Jiankang (Jianye, present-day Nanjing) was as the capital for about 330 years. The development of water system had brought prosperity to agriculture. Handicraft industry and commerce were gradually emerging. The continuous development and expansion of city brought technological, cultural and artistic progress. At that time, Nanjing became the largest metropolis in the world.

At the beginning of Ming Dynasty (1368-1644AD), Emperor Zhu Yuanzhang set Yingtianfu (Nanjing) as imperial capital. Nanjing was the national political centre in the following decades and still played an important political role in Qing Dynasty (1644-1912AD). Nanjing was built with tall city walls, which were the longest in the world at the time. For the capital status, the convenient transport was an important aspect. The food supplies consumption was great in such

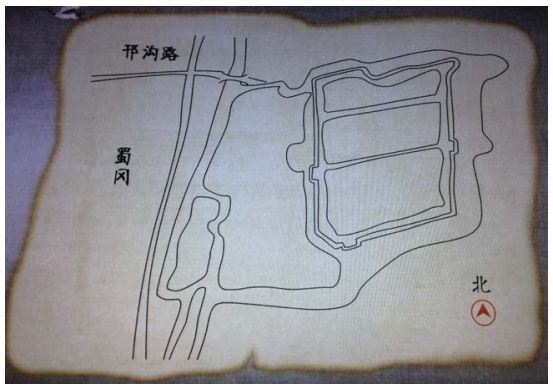

(a)

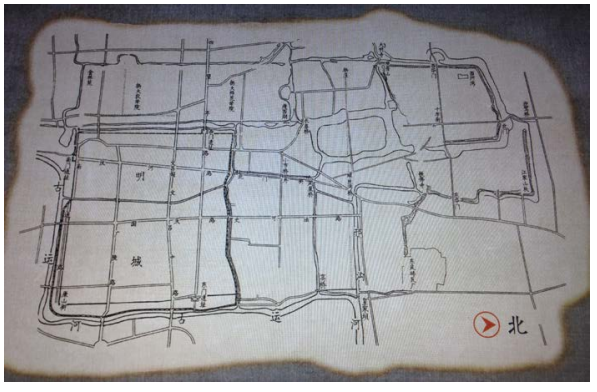

(b)

Figure 1. (a) Han City in 486 BC Source: Yangzhou Museum; (b) Yangzhou City in Ming Dynasty (1368-1644 AD). 
large-scale and populous capital, and so that the rich resources in Taihu Lake basin became the main supply area of Nanjing, the Yangtze River and the Qinhuai River (Qinhuai River was far wider than it is now) were the main channels for transporting. In the year of 1393, in order to change the long lines of delivering, Emperor Zhu Yuanzhang ordered to dig the Yanzhi River, thus the Qinhuai River and Shijiu Lake directly communicated, avoiding the risks of waves in Yangtze River (Figure 2).

\subsection{Suzhou: From "a City" of Jiangdong Area to the National Economic Centre}

Suzhou is the intersection place at the north-south canal and Lou River, with

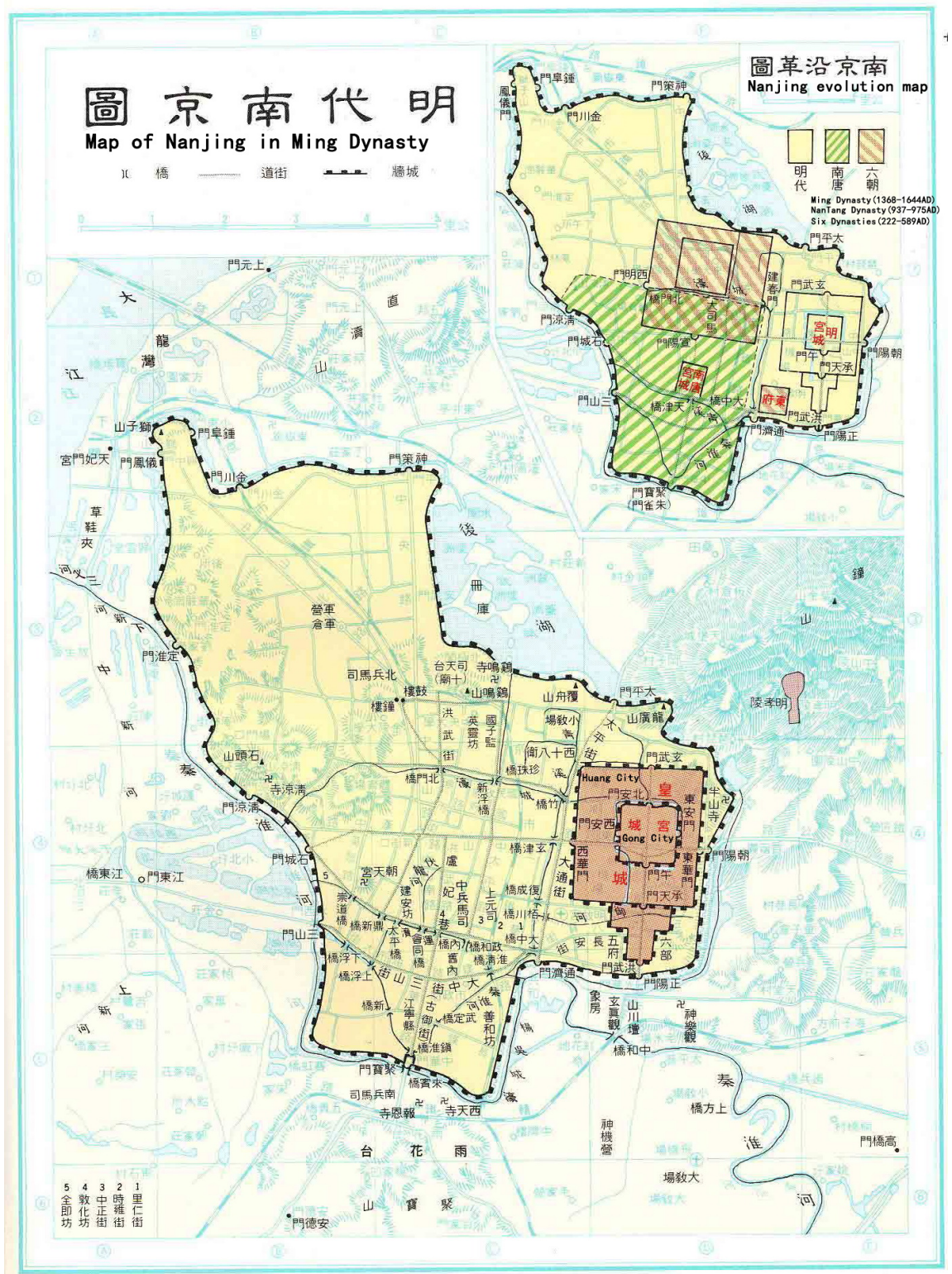

Figure 2. Map of Nanjing in Ming Dynasty. Source: Historical Atlas of China, Chinese culture university, 1980. 
favourable conditions of inland navigation and maritime traffic. The water system of Suzhou drained into the sea by three rivers (Lou river, Song river, Dong river), and also, it could flow into the Yangtze River through the canal system, linking up with the Huai River. Canals and the specific water system were the stabilizing factors for Suzhou city's location. The river system of Suzhou was divided into three levels: the first was external moat outside the city and the canals, the second was known as the "three horizontal and four vertical lines" river system. The third one was the large number of inner tributaries of main rivers across the city. In addition to defence, the city moat had more communication with the canals and the inner rivers. Rivers in the city were mainly used for adjusting and connecting to the lateral branches of the rivers, making the city water level and velocity of flow generally consistent. While the remaining branches of rivers linked with ditches, for the purpose of domiciliary transport, flooding control and draining.

During the Spring and Autumn Period (770-476BC) and the Warring States Period (476-221BC), due to the needs of the development of military politics, the king of $\mathrm{Wu}$ dug a lot of east-west, north-south canals form the capital of $\mathrm{Wu}$ (Suzhou) to its surroundings, forming a group of cities. Since Sui Dynasty (581-618AD), Suzhou became the shipping centre of Jiangnan canal. The opening of the canal did not only make Suzhou well-communicated with Central Plains (comprising the middle and lower reaches of the Huanghe River), but also the commodity economy was well-developed, its handmade products, all crops were exported to the North. Simultaneously, the canals coordinated the cities' inner water system better, improving the urban environment a lot.

From the middle of Tang Dynasty (618-907AD) until the end of Northern Song Dynasty (960-1127AD), Suzhou received a large number of migrants from the North, and slowly developed into a "metropolis". Relying on the city's water system and the channels, the buildings were along the rivers and distributed regularly. Bridges linked most of these buildings, which became a significant feature of Suzhou urban development. Urban construction formed a "double checkerboard" pattern of land and water transport. In addition, the amount of gardens, education institutions, markets and lanes stimulated the building of restaurants, tea houses and other amusement facilities. Another important feature of this period of urban construction, the military facilities significantly enhanced, the wall and moat were much stronger. The city map of NanSong Dynasty called "Pingjiang map" presenting the city's prosperous was the oldest city map in ancient China. Later on it attrected retired officials and wealthy businessmen to build gardens, so that the small and exquisite gardens were throughout the city, the garden art reached a historical peak, beautified the urban environment (Figure 3).

\subsection{Shanghai: From a Small Fishing Village to a Cosmopolitan City}

Shanghai was actually a small fishing village during the Spring and Autumn 

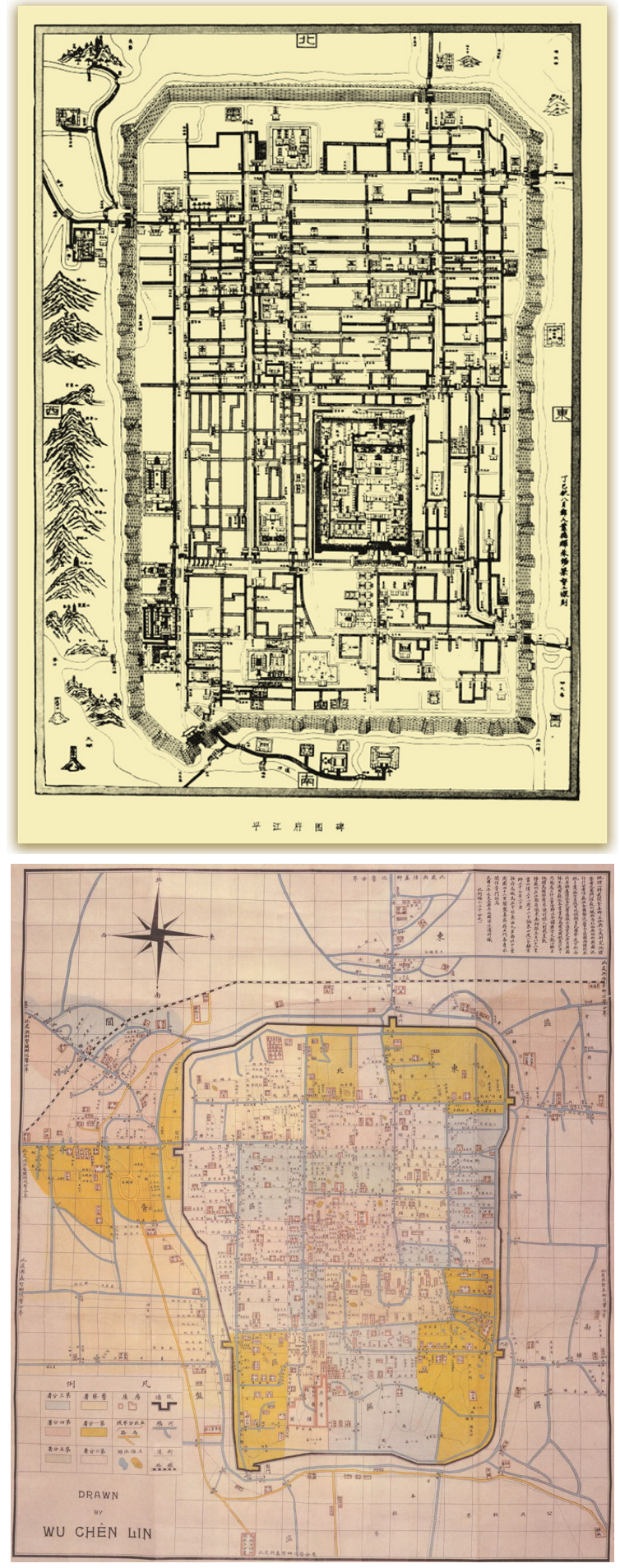

Figure 3. Pingjiangfu Map in 1229 ADMap of Suzhou in 1914AD. Source: Internet.

Period (770-476BC) and the Warring States Period (476-221 BC), At that time, the Wusong River was called "Hudu", while "Hu" was a fishing tool, hence Shanghai was later referred to as "Hu" [3]. In Qin dynasty, today's Shanghai Tuolin town area had been one of the famous sea salt production areas in China. 
About 4500 years ago, the agriculture was the main economic activities in the area of present-day Shanghai, as the coastline moved eastward, Shanghai area gradually developed into an important grain-producing areas.

Shanghai was called Huating County in Tang Dynasty, which was considered the first town in Shanghai built in the administration organization system, and had been thriving with the development of water transport since that. In Song Dynasty (960-1279AD), it was named Shanghai Town, at that time, Shanghai was already a gathering place for businessmen and traders as a new trade port. With the increasingly prosperous cotton industry and the rising of cotton textile industry, Shanghai became "a giant town" in Yuan Dynasty (1271-1368AD). In the year of 1553, city walls were erected around Shanghai County and the urban institution was basically formed. Shanghai in Ming Dynasty (1368-1644AD) had become the hub of transporting and storing the grain and food supplies. Because of the economic development of the Jiangnan and the enhancement of internal and external trade in Shanghai, in the middle of the 19th century, Shanghai had grew up into a bustling harbor.

Good port condition promoted the rapid development of Shanghai. Another important reason of Shanghai's rapid rise in latest two hundred years was western colonial influence. Shanghai was opened as a treaty port on November 1843. In 1927, Nanjing National Government of the Republic of China was founded, and Shanghai was instituted into a special municipality, with a lot of urban plannings were followed. By the late 1920s, Shanghai's transport network was becoming more and more well-developed, especially Shanghai-Nanjing Railway. Under the joint action of inner and external forces, Shanghai had gradually become the biggest metropolis and an industrial and commercial center in China (Figure 4).

\section{Delta Governance of the Yangtze River Delta}

Water system plays an important role in the process of urban development, and shapes the various forms in the perspective of the urban material space in different periods. The factors of urban governance are the dynamic mechanism that influence the development of the cities. In the early time, nature, military "manufactured" waterways (natural and artificial), brought the emergence of the cities, as seen in the birth of Yangzhou, Suzhou. Early human settlements evolved around the Yangtze River and Tai Lake, with humid climate that suitable for the growth of rice. The areas at the intersection of rivers and on the high ground of plains became the wonderful place for a regional central city. Driven by military and political needs, a lot of regional canals were dug, promoting the birth and development of cities. Jiangnan Canal, Zhuyu Canal and the dredging of Han Canal in Qin and Han Dynasties (221BC-220AD), Pogangdu Canal in Six Dynasties (222-589AD), Shanyang Canal in Sui Dynasty (581-618AD) and so forth. The main purpose of each canal was for hegemony and defence. But they were also beneficial to the irrigation and promoted the growth of surrounding cities. 

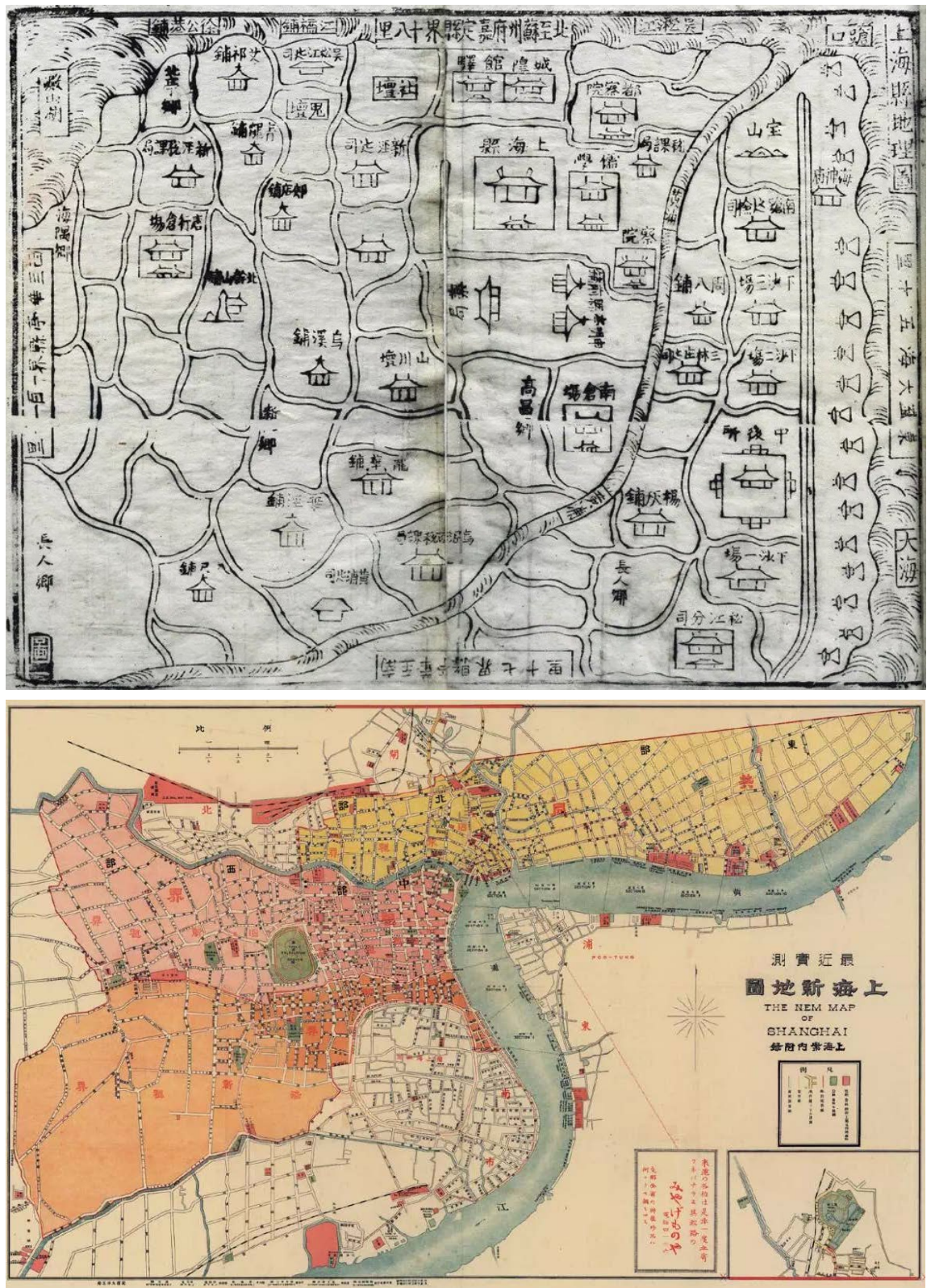

Figure 4. Map of Shanghai in 1504AD Map of Shanghai in 1917. Source: Complete Atlas of Shanghai antiquated maps, 2017.

In the medium period, national power forces (government), the transport-sector (the Grand Canal adminsitration) and the economic interchanges (North-South and East-West) "arranged" the water management, such as building new canals, constructing the locks, and dredging the rivers, stimulating prosperity of the cities, as seen in Nanjing in Six Dynasties, Yangzhou in Tang Dynasty, Suzhou in Song Dynasty. With the improvement of the productivity and the development of a commodity economy, and the instability in the north by the frequent wars around its political centre, a large number of population migrated to the South, brought advanced technology, resulting in a national economic boast gradually moving to the South. In order to supply the political 
centre in the North, transporting abundant supplies from the South was urgent. The mileage of canals and the dredging of waterways became more and more important. The canals also extended from regional to national areas. In addition, since Qin Dynasty until Qing, the canals extended from the capital to the target regional areas of hegemony, promoting the development and prosperity of the cities along them. At these times there were more than thirty Chinese most important economic metropolises, and eleven located along the line of the Grand Canal [4]. Furthermore the shape of the urban spatial landscape was also affected by the economy. The main factor that determined the changes of the city of Yangzhou was the development of socio-economic and natural environment. When the canals were only used by the military, the city was not at the edge of the canals. While the function of the canals were converted to economic use, the city developed along the bank of the canals. In the south of Jiangsu Province, it presented market towns, which was strengthened by their urban economic functions. The streets were no longer flanked by walls, but by stores, restaurants, and taverns. The architectures facing streets were usually shops with a residential yard at the back or multi-story buildings adjacent to each other. Water transport and the establishment of national canal transport agency headquartered in the city of Huai'an, promoted the economic development, contributing the city growing up to the regional political and military and trade centre city. The same influence had the salt commissioner station of Lianghuai in Yangzhou [5].

Next to the economy, also the institutions "influenced" the form and layout of the cities. In the Spring and Autumn Period and the Warring States Period (770 BC-221BC), "Water Order" was the China's first irrigation management system. During Han Dynasty (202BC-220AD), Si Maqian created the "Historical Records. Waterways", which was the first book that described the brief history of Chinese water conservancy. It introduced systematically the ancient Chinese water conservancy and its impact on the national economy and people's livelihood [6]. The "Regulations of Water Conservancy" was the earliest extant national water legislation, The "Irrigation And Water Conservancy Constraint" and the "River Defense Order" about flood control in Song Dynasty (960-1279AD), such a large number of water conservancy science and technology works turned up. This also induced a kind of water culture to affect the urbanization. In the area of Yangtze River Delta of Jiangsu Province, Wu Culture, Jiangnan Culture, Liuchao Culture and so on was the internal dynamic mechanism of urban development, influencing the city life and the appearance of functional architectures. The temples, gardens, business halls and so forth were the embodiment of culture in physical form. These three factors, actors, institutions interplayed each other, joint creating the urban morphology of the Yangtze River Metropolitan Delta.

\section{Learning about Future Challenges}

Water has the function for consolidating the city sites, promoting the industrial 
and commercial development, improving the living environment. In the farming period, the Yangtze River Delta Basin`s water network was densely distributed. Taihu Lake, the Yangtze River, the canals and the natural rivers formed a network of water transportation system. When the Yangtze River Delta had entered into the industrial era with the springing up of the modern industry and commerce, cities were centralised along the railways and highways, the status of water transport declined gradually. At present, the meaning of Yangtze River Delta is more in the economic sense, and its regional relations and scope are more extensive. It has formed the core area of Shanghai, Nanjing metropolitan area, Suzhou-Wuxi-Changzhou metropolitan area, Hangzhou metropolitan area and Ningbo metropolitan area. The Yangtze River Delta is coming into being a urban network pattern supporting by the high speed road and railway network, and they are growing into a highly integrated giant metropolis [2].

For restoring the age old water adaptive capacity of ancient urban formations and communities, we should learn from successful historical experiences to take the approaches of socio-cultural resilience in order to deal with the future challenges. From the history, We should respect the regional landscape pattern, and have a profound understanding of the city and the surrounding geological features ,so as to pursuit the natural sustainable development. Integrating the city and environment into the same regional system and establishing the ecological relationship between the city and the suburb. History will be a resource to achieve progress in future urban development. Water environment as the linear historical context and important part of the historical landscape, with landmark historical buildings and rich human activities, it will form successional and operational historical landscape. About the planning and design of waterfront areas, it advices the urban constructions be back to face the water, restore historical memory and the social-culture resilience, combine with modern planning and human activities, in line with urban ecological development requirements, realizing the "resilient" development.

\section{References}

[1] Tang, Z.L. (2017) A River and a City. http://www.shobserver.com/news/detail?id $=48120$

[2] Wang, Y., Dong, W. and Boelens, L. The Interaction of City and Water in the Yangtze River Delta: A Natural/Artificial Comparison with Euro Delta.

[3] Shanghai Planning Exhibition Hall.

[4] Fu, C. (1985) The History of Chinese Canal Cities Development. Sichuan People's Publishing House, Chengdu.

[5] Nanjing Museum.

[6] China Science Communication. 